\title{
Investigating the Effect of Geocell Changes on Slope Stability in Unsaturated Soil
}

\author{
Behnam Mehdipour, Hamid Hashemolhosseini, Bahram Nadi, Masoud Mirmohamadsadeghi
}

\begin{abstract}
The purpose of this research is to investigate the performance and efficiency of reinforced slope in the stability of geocell layers in unsaturated soil conditions. Slope reinforced with geocell acts like a beam in the soil due to the geocell having a height (three-dimensional). Due to its flexural properties, it has moment of inertia as well as bending strength, which reduces the displacement and increases the safety factor of the slope. Taking into consideration unsaturated conditions of soil contributes a lot to making results close to reality. One of the well-known models among elastoplastic models for modeling unsaturated soils is Barcelona Basic Model, which has been added to the FLAC2D software by codification. Changes in thickness, length and number of geocell layers are remarkably effective on slope stability. The results show that the geocell's reinforcing efficiency depends on the number of layers and depth of its placement. As the depth of the geocell's first layer increases, the lateral and vertical side elevation of the upper part of the slope increases with respect to the elevation. Load capacity increases with increasing geocell length. By increasing the length of the geocell layer, the joint strength, the mobilized tensile strength, and the bending moment are increased. At $\mathrm{u} / \mathrm{H}=0.2$, an increase in the bending momentum of about $20 \%$ occurs with increasing geocell thickness. In $\mathrm{u} / \mathrm{H}=1$, the increase in bending momentum is $10.4 \%$. In addition, by increasing the thickness of the geocell, the Value of moment of the inertia increases and, as a result, the amount of geocell reinforcement bending moment increases.
\end{abstract}

Keywords: Barcelona Basic Model; FLAC2D; geocell; slope; unsaturated soil

\section{INTRODUCTION}

Different studies have been conducted on reinforced soil slope. The effect of length and distance of reinforcements on the behavior of reinforced soil slope has been widely examined. The obtained results revealed that as the distances between reinforcements increase, the available load in reinforcement layers and consequently wall deformation increase as well. To investigate the failure mechanism of geosynthetic-reinforced soil slope and evaluate the design hypothesis and design methods for such walls, numerical and experimental studies have been carried out showing that the failure surface is different from the propagation of failure region; rather, its location is dependent on geometry, strength, and stiffness of reinforcement elements [1-6]. Employing geocell to reinforce soils has broad applications as an effective and rapid method in civil projects. Geocellreinforced soil is mainly used to resist static and cyclic loads. In fact, this reinforcement is used to increase the load-bearing capacity of soft soil and decrease settlement and displacements of slopes. Geocell functions as a layer confining soil and prevents the soil from moving outward the loading region. Furthermore, soil swelling is reduced, which leads to some variations in the factor of safety of slope. Geocell increases the bending, tensile and shear strengths of soil and, due to its height, functions as a beam providing moment of inertia and consequently bending strength. Although bending stiffness is low with respect to thickness, it can diminish deformations of layers and cause reduction in the settlement of soil-structure system [7].

Fakher and Jones [8] investigated the effect of bending stiffness of geogrid reinforcement using Flac software. Their results show that although bending stiffness is low with respect to the small thickness of geogrid layer, it can diminish the deformation of geogrid layer and consequently decrease the system settlement [8].
Zhang et al. $[9,10]$ simulated the performance of geocell reinforcement considering the resistance of contact surface between soil and geocell and assumed the geocell reinforcement as a beam on an elastic bed.

Dash et al. [11] observed through an experimental effort that the geocell layer functioned as a beam with bending behavior. Their results illustrated that as the height of geocell layer increases, the behavior of deep beam becomes dominant in geocell layer. Yang et al. [12] indicated that geocell benefits form a relatively high bending strength where it is necessary to incorporate bending stiffness in modeling geocell layer.

The present study uses beam element in FLAC2D software to incorporate the properties of geocell layer in the simulation of geocell reinforcement.

Construction projects carried out using more advanced technologies are increasingly developing. One of the restrictions on such projects is the inappropriateness of project implementation site as the structure foundation. Recognition of the land appropriateness to construct the foundation requires the knowledge and expertise of engineers and researchers about the soil behavior in different conditions and states. In other words, researchers should be aware of the variation in soil behavior under different circumstances so as to provide a qualitative and quantitative evaluation of the soil behavior in different conditions. However, the principles of classic soil mechanics founded by Carl Tarzaghi are mostly associated with saturated soils $[13,14]$.

Unsaturated soil is not a specific type of soil but rather a state of soil that can occur for all types of soil based on the filling fluid. Saturation or unsaturation in any region is affected by environmental factors, namely rainfall, evaporation, and rise of groundwater level. In other words, all soils are subjected to either wetting or drying. Therefore, change in the state of pore-water pressure and occurrence of unsaturated conditions are probable for all soils [15]. 
Full drying conditions of soil, particularly for granular soil, might experience a reduction in the factor of safety by wetting and moisture absorption at the end of construction stages. Moreover, since the shear strength of soil is drastically affected by the degree of soil saturation, it is important to consider correct conditions of saturation or unsaturation of soil once investigating the soil behavior. In fact, although the design is more simplified in geotechnical engineering by not considering unsaturated soil conditions, it increases most of the construction costs [16].

Morgenstern in 1978 [17] proposed a relation to express the shear strength of unsaturated soils where the shear strength was properly separated due to effective stress from the shear strength induced by net stress. In recent years, the effective stress method has been of great interest to many researchers to determine the shear strength of unsaturated soils [18-21].

In 1998, a relation was proposed based on effective stress, cohesion, and internal friction angle of soil to express the shear strength of unsaturated clay [22]. On the other hand, the effective stress of unsaturated soils is in direct proportion to the extent of matric suction within the soil. In this regard, Alonso et al. were among pioneers and their study attracted a great deal of attention such that one can find a large number of basic models in the respective scientific references. [15]

This model, as the most known model proposed in the analysis of unsaturated soil, functions on the basis of three major concepts including state surfaces, soil critical state, and empirical tests. This model can be considered as the development of critical state in unsaturated state considering the effect of suction phenomenon [23].

The result of most studies is summarized in the following three parts:

A- Fundamentals of stress states and principal variables employed to create numerous models

B- Precise analysis of basic models and investigation of their strengths and weaknesses

C- Progress in the modelling unsaturated soil [14].

\section{THEORY}

\subsection{Barcelona Basic Model}

The present study has used the Barcelona Basic Model that works elastoplastically and is applied to express the stress-strain of unsaturated soils based on stiffening plasticity. This model was first proposed by Alonso in 1990 at Polytechnic University of Catalonia. It is founded on the basis of Cam-Clay Model and capable of expressing many principle facets of the behavior of unsaturated soils, namely silty soils, clayey sands, sandy clay, and clay with low plasticity. It is worth noting that this model has been proposed with the purpose of expressing the behavior of partially saturated soil with low or medium inflation capability. This model is one of the most known proposed models to analyze unsaturated soils which is based on three major principles including state surfaces, soil critical state, and empirical tests. This model can be considered as the development of critical state in unsaturated state considering the effect of suction phenomenon. The Barcelona Basic
Model has two independent stress variables in the form of net stress and soil suction. [10]

$$
\begin{aligned}
& \bar{\sigma}_{i j}=\sigma_{i j}-\partial_{i j} u_{i j} \\
& S=u_{\mathrm{a}}-u_{\mathrm{w}}
\end{aligned}
$$

Where $\bar{\sigma}_{i j}$ stands for net stress tensor, $\sigma_{i j}$ denotes total stress tensor, $\partial_{i j}$ is Kronecker delta, $S$ is soil suction, $u_{\mathrm{a}}$ stands for pore-air pressure, $u_{i j}, u_{\mathrm{w}}$ is pore-water pressure. The relations of Barcelona Basic Model are written based on four variables including net mean stress $P$, deviatoric stress $q$, nest suction $S$, and specific volume $v$.

$$
\begin{aligned}
& P=\frac{\sigma_{1}+\sigma_{2}+\sigma_{3}}{3} \\
& q=\frac{1}{\sqrt{2}} \sqrt{\left(\sigma_{1}-\sigma_{2}\right)^{2}+\left(\sigma_{2}-\sigma_{3}\right)^{2}+\left(\sigma_{1}-\sigma_{3}\right)^{2}}
\end{aligned}
$$

Where $\sigma_{1}, \sigma_{2}, \sigma_{3}$ are the principal stresses of soil. If the soil is isotopically loaded at constant suction until the net mean stress across the normal consolidation line (NCL), the specific volume is obtained by the following relation.

$$
v=N(s)-\lambda(s) \ln \frac{P}{P^{\mathrm{c}}}
$$

Here $\lambda(s)$ is the stiffness parameter along the normal consolidation line at constant suction $S$, and $P^{\mathrm{c}}$ stands for the reference pressure in $v=N(s)$. If unloading and reloading occur at constant suction, then the soil behavior is assumed as elastic. A constant suction is considered for all surfaces in the Barcelona Basic Model. The stiffness parameter on the normal consolidation line is defined at a constant suction as follows:

$$
\lambda(s)=\lambda(0)[(1-r) \exp (\beta s)+r]
$$

$r$ is a parameter defining the maximum soil stiffness and $\beta$ controls the soil stiffness increase rate induced by suction. Similar to the actions due to the applied net stress, suction also yields elastic and plastic strains. Once the soil reaches the already-experienced maximum suction, the irrecoverable strain is initiated [23].

In the Barcelona Basic Model, partial volumetric strain $\mathrm{d} \varepsilon_{\mathrm{v}}$ depends on the variations of net mean stress, given as the following relation.

$$
\begin{aligned}
& \mathrm{d} \varepsilon_{v}=\mathrm{d} \varepsilon_{1}+\mathrm{d} \varepsilon_{2}+\mathrm{d} \varepsilon_{3} \\
& \mathrm{~d} \varepsilon_{q}=\frac{\sqrt{2}}{3} \sqrt{\left(\mathrm{d} \varepsilon_{1}-\mathrm{d} \varepsilon_{2}\right)^{2}+\left(\mathrm{d} \varepsilon_{2}-\mathrm{d} \varepsilon_{3}\right)^{2}+\left(\mathrm{d} \varepsilon_{1}-\mathrm{d} \varepsilon_{3}\right)^{2}}
\end{aligned}
$$

The partial strain induced by net mean and deviatoric stresses are divided into two components, namely elastic 
strain $\mathrm{d} \varepsilon^{\mathrm{e}}$ and plastic strain $\mathrm{d} \varepsilon^{\mathrm{p}}$. On the other hand, the partial volumetric strain, due to the suction decrease by wetting or the suction increase by drying, is found to be purely elastic.

$$
\mathrm{d} \varepsilon=\left(\mathrm{d} \varepsilon^{\mathrm{e}}+\mathrm{d} \varepsilon^{\mathrm{p}}\right)_{\mathrm{p}}+\left(\mathrm{d} \varepsilon^{\mathrm{e}}+\mathrm{d} \varepsilon^{\mathrm{p}}\right)_{\mathrm{s}}
$$

This model consists of a suction decrease yield curve showing that the effect of suction change on the soil state to reach the yield point is as important as the effect of variation in the net mean stress. The volumetric elastic strain is generated by the net mean stress in the elastic region.

$\mathrm{d} \varepsilon_{v p}^{\mathrm{p}}=\frac{k}{v} \frac{\mathrm{d} p}{p}$

When the net mean stress meets the pre-consolidation stress $p_{0}$ at the constant suction $S$, the soil is still in the normal consolidation state and the total volumetric strain is obtained by Eq. (11).

$\mathrm{d} \varepsilon_{v p}^{\mathrm{p}}=\frac{\lambda(s)}{v} \frac{\mathrm{d} p_{0}}{p_{0}}$

Therefore, the plastic volumetric strain is defined by the subtraction of the elastic volumetric strain from the total volumetric strain.

$\mathrm{d} \varepsilon_{v p}^{\mathrm{p}}=\frac{\lambda(0)-k}{v} \frac{\mathrm{d} p^{*}}{p^{*}}$

Similarly, elastic, plastic, and total volumetric strains dependent on suction variations are given by relations (13), (14), and (15), respectively.

$\mathrm{d} \varepsilon_{v k}^{\mathrm{p}}=\frac{k_{s}}{v} \frac{\mathrm{d} s}{s+p_{\text {atm }}}$

$\mathrm{d} \varepsilon_{v s}=\frac{\lambda(s)}{v} \frac{\mathrm{d} s_{0}}{s_{0}+p_{\mathrm{atm}}}$

$\mathrm{d} \varepsilon_{v s}^{\mathrm{p}}=\frac{\lambda(s)-k s}{v} \frac{\mathrm{d} s_{0}}{s_{0}+p_{\mathrm{atm}}}$

Thus, once the yield state occurs, the increment of preconsolidation pressure and yield suction can be presented using stiffening rules, given by the following relations.

$\frac{\mathrm{d} p_{0}^{*}}{p_{0}^{*}}=\frac{v}{\lambda(0)-k} \mathrm{~d} \varepsilon_{v p}^{\mathrm{p}}$

$\frac{\mathrm{d} s_{0}}{s_{0}+p_{\mathrm{atm}}}=\frac{v}{\lambda(s)-k_{s}} d \varepsilon_{v p}^{\mathrm{p}}$

Here $k_{\mathrm{s}}$ is the stiffness parameter for suction change in the elastic region. In the states of total stress, deviatoric stress $q$ defines the effect of shear stress. The Barcelona Basic Model suggests that the shear strength increases by suction. It is a general attribute of partially saturated soils which is obtained by adding apparent cohesion $p_{s}$.

$p_{s}=k s$

Here $k$ defines the cohesion increase by suction increase. The critical state line at each constant suction $(s)$ is horizontal in saturation conditions (Fig. 1).

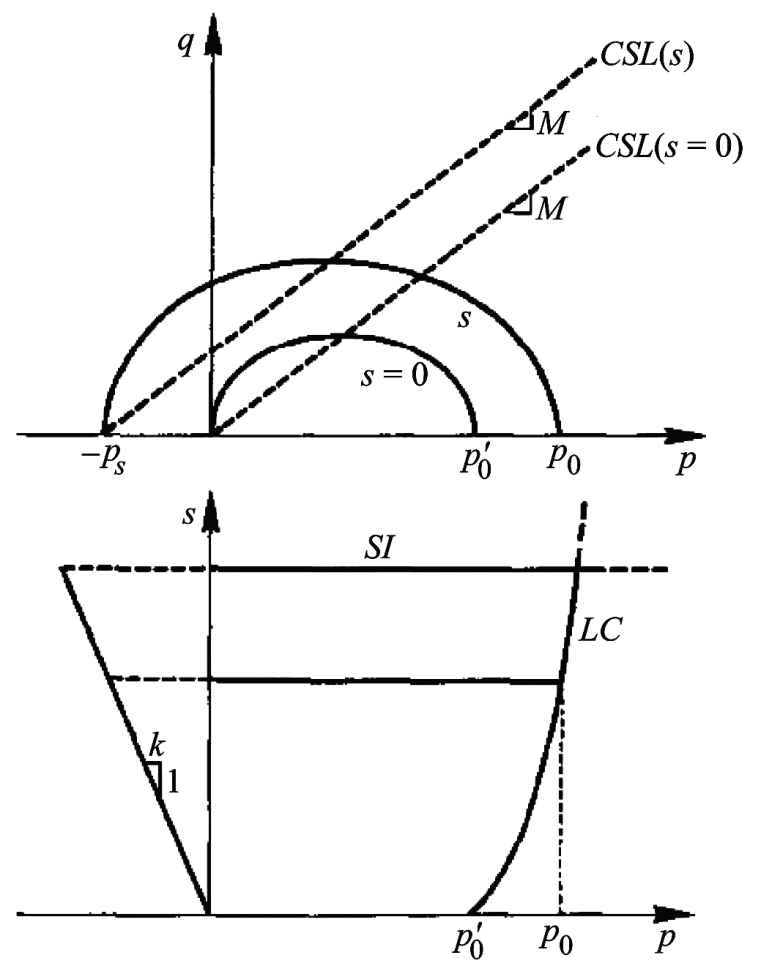

Figure 1 Failure surface in space $(s, p, q)$ [23]

The respective equation for the critical state line is as follows:

$f=q^{2}-M^{2}\left(p+p_{s}\right)\left(p_{0}-p\right)$

Where, $M$ is the slope of critical state line. The nonassociated flow rule is applied to accurately estimate the correct value of $k_{0}$.

$\frac{\mathrm{d} \varepsilon_{s}^{\mathrm{p}}}{\mathrm{d} \varepsilon_{v p}^{\mathrm{p}}}=\frac{2 q \alpha}{M^{2}\left(2 p+p_{s}-p_{0}\right)}$

Here $\alpha$ is the parameter of non-associated flow rule relation (20). The strain caused by changing deviatoric stress is obtained by relation (21).

$\mathrm{d} \varepsilon_{q}^{\mathrm{p}}=\frac{1}{3 G} \mathrm{~d} q$ 
FISH is employed to codify the Barcelona Basic Model in FALC2D. The codification method of Barcelona Basic Model is very identical to the modified Cam-Clay Model.

\subsection{Water-Soil Characteristic Curve}

Numerous functions have been proposed so far to describe a water-soil characteristic curve. The present study has benefited from the model proposed by Van Genuchten. This model is defined by relation (22).

$$
\frac{\theta-\theta_{r}}{\theta_{s}-\theta_{r}}=\frac{1}{\left[1+(\alpha \psi)^{n}\right]^{m}}
$$

Here $\alpha, m$, and $n$ are fitting parameters. $\psi$ stands for soil suction and $\theta_{s}, \theta_{r}$ are residual water content and saturated water content, respectively. The slope of curve is affected by $m$ at higher values of suction. $m$ and $n$ are correlated according to relation (23).

$$
m=1-\frac{1}{n}
$$

Replacing relation (23) in relation (22), the general relation for the function of water-soil characteristic curve is obtained. Regarding this relation, a certain amount of suction is reached for any specific degree of soil saturation [24, 25].

$$
\frac{\theta-\theta_{r}}{\theta_{s}-\theta_{r}}=\frac{1}{\left[1+(\alpha \psi)^{n}\right]^{\left(1-\frac{1}{n}\right)}}
$$

Values for relation (24) are represented in Tab. 1. They are based on SWCC curve with the regression $R^{2}=0.942$ (Fig. 2).

Table 1 Parameters of the relation for water-soil curve

Table 1 Parameters of the relation for water-soil curve
\begin{tabular}{|c|c|c|}
\hline$\theta_{s}$ & $\theta_{r}$ & $\alpha\left(\mathrm{m}^{-1}\right)$ \\
\hline 0.48 & 0.1 & 0.3 \\
\hline
\end{tabular}

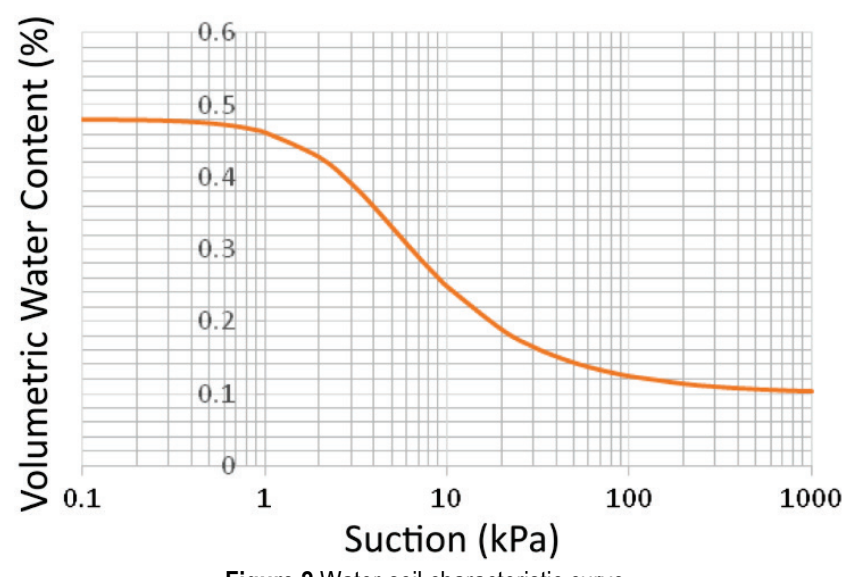

Figure 2 Water-soil characteristic curve

\subsection{Geocell}

Due to the three-dimensional structure, the geocell results in side enclosure of the particles of soil inside the cells. Also, geocell reinforcement causes the vertical enclosure of the soil within the geocells in two ways. Firstly, through the friction between the soil-cellular materials formed by the walls of the cell. Secondly, the geocell reinforcement acts like a soil enclosure layer that prevents soil movement outside of the loading zone [26]. The decorative effect of the geocell layer is also enhanced by the force of tensile strength in the geocell's reinforcement due to resistance to vertical loads (Fig. 3).

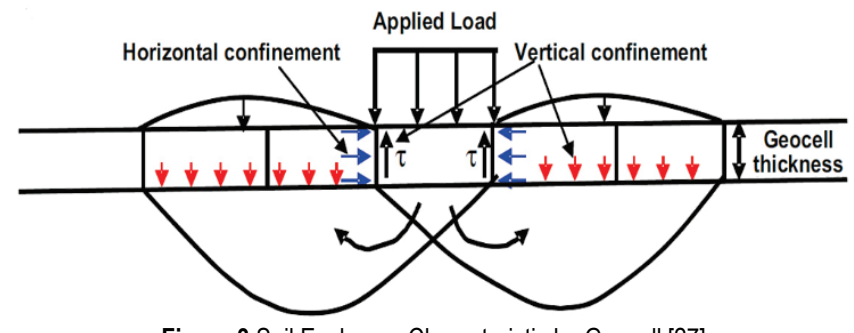

Figure 3 Soil Enclosure Characteristic by Geocell [27]

Contact resistances due to interactions between the geocell and the soil of the two sides of the geocell layer increase the lateral enclosure and reduce lateral strain. As a result, the modulus of elasticity of the geocell-soil system increases. (Fig. 4).

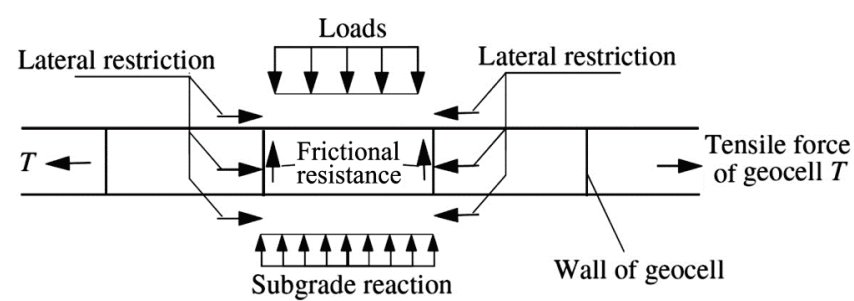

Figure 4 The effect of lateral resistance of the geocell reinforcement [28]

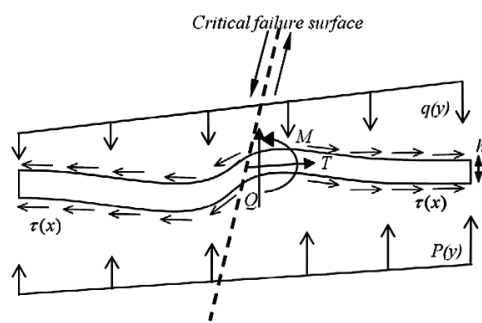

a)

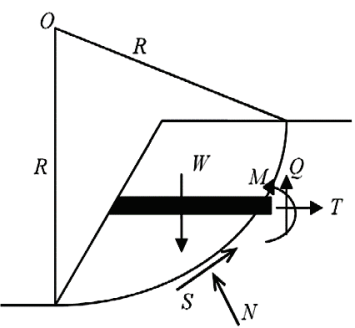

b)
Figure $\mathbf{5}$ a) Failure mechanism of geocell reinforcement, b) forces acted on the geocell [29]

Geocell reinforcement has tensile and shear force in the interface of soil and geocell. Furthermore, due to having thickness and elasticity modulus, it offers moment of inertia and consequently bending moment. As it can be observed in (Fig. 5). T, $M$, and $Q$ are tensile force, bending moment, and shear force of geocell, respectively. $q(y)$ is applied to the upper part of geocell layer while $p(y)$ induced by the bed 
reaction is acted in the lower part of geocell layer. $h$ is the thickness of geocell reinforcement and $T(x)$ is the strength of the soil-geocell interface.

Normal and shear forces causing the response of adjoining elements are calculated using the following equations at $t+\Delta t[30]$.

$$
\begin{aligned}
& F_{n}^{(t+\Delta t)}=K_{n} u_{n} A+\sigma_{n} A \\
& F_{s i}^{(t+\Delta t)}=F_{s i}^{(t)}+K_{s} \Delta u_{s i}^{(t+0.5 \Delta t)} A+\sigma_{s i} A
\end{aligned}
$$

Where, $F_{n}^{(t+\Delta t)}$ is the normal force at $t+\Delta t, F_{s i}^{(t+\Delta t)}$ is the shear force at $t+\Delta t, u_{n}$ stands for the absolute penetration of the adjoining element node perpendicular to the targeted surface, $\Delta u_{s i}^{(t+0.5 \Delta t)}$ is relative shear displacement, $\sigma_{n}$ is normal stress, $K_{n}$ and $K_{s}$ are normal and shear stiffness, respectively, $A$ is the specified area allocated to each node, and $\sigma_{s i}$ is the extra shear stress due to the stress generated in the adjoining element. The values of normal and shear stiffness are calculated using the following relation [27].

$k_{n}=k_{s}=10 \times \max \left[\frac{k+\frac{4}{3} G}{\Delta z_{\min }}\right]$

Here $k$ is bulk modulus and $G$ is soil shear modulus. $\Delta z_{\min }$ is the width of the smallest adjoining zone in the normal direction. [31]

\section{NUMERICAL MODEL}

The Barcelona Basic Model is a soil behavioral model used to investigate the reinforced slope. This model is added to the finite difference Flac software through codification. In FISH code written based on the triaxial test for validation of the Barcelona Basic Model, the generation algorithms of $p$, $q, v, \varepsilon, S$ (suction) have been predicted. Soil properties are given in Tab.1.

Table 1 Model parameters [23]

\begin{tabular}{|c|c|l|}
\hline Parameter & Value & \multicolumn{1}{|c|}{ Description } \\
\hline$G$ & $3.3 \mathrm{MPa}$ & Shear modulus \\
\hline$M$ & 0.82 & Slope of critical state line \\
\hline$\lambda$ & 0.14 & Slope of modified isotropic line \\
\hline$K$ & 0.015 & Slope of elastic inflation line \\
\hline$\beta$ & $16.4 \mathrm{MPa}^{-1}$ & $\begin{array}{l}\text { The parameter that controls the soil stiffness } \\
\text { increase using suction. }\end{array}$ \\
\hline$r$ & 0.26 & $\begin{array}{l}\text { Constant value associated with the maximum } \\
\text { soil stiffness }\end{array}$ \\
\hline$k$ & 1.24 & Cohesion increase by suction increase \\
\hline$k_{s}$ & 0.01 & Elastic stiffness parameter for suction change \\
\hline$v$ & 1.915 & Poisson's ratio \\
\hline$P^{\mathrm{c}}$ & $0.043 \mathrm{MPa}$ & Reference pressure \\
\hline \multicolumn{2}{|l}{} \\
\end{tabular}

The conditions of numerical modeling are summarized in four main steps, namely generation of model geometry and reinforced slope, setting boundary conditions and respective stresses, running the program to approach initial equilibrium, and finally investigation of the factor of safety and deformation of reinforced slope and bending variations of geocell in the unsaturated state of soil. The concerned slope has a width of $50 \mathrm{~m}$ and a height of $30 \mathrm{~m}$. The sensitivity analysis and modeling have been conducted to select the optimum limit such that any further increase in the limit yields no change in results and merely increases the computational time. Due to the symmetry, only half of the slope has been modeled. The symmetry line is positioned on the right side of the model. To analyze the model more precisely as to determine the factor of safety (FOS) and deformation of the reinforced soil slope, a finer mesh is applied. Moreover, the mesh size becomes larger once moving away from the slope so as to reduce the computational time. The lower boundary of the model has been fixed against any movement and displacement in all directions while the vertical boundary in solely constrained in the horizontal direction (Fig. 6). The investigated parameters to address the effect of geocell reinforcement on the factor of safety and failure surface are as follows: $(u)$ depth of the first geocell layer measured from the slope top level, $(N)$ number of geocell layers, $(h)$ height of geocell layer, and $(L)$ length of geocell layer. To simplify the obtained results, the dimensionless form of all available parameters have been expressed with respect to the slope height (e.g. $u / H$ or $L / H$ ).

The secant modulus of geocell $(M)$ has been set to 150 $(\mathrm{kN} / \mathrm{m})$ at a strain of $2.5 \%$. Furthermore, the tensile strength and thickness of geocell has been considered to be $60(\mathrm{kN} / \mathrm{m})$ and $0.5 \mathrm{~m}, 0.1 \mathrm{~m}$ respectively. The Modulus of elasticity has been $50 \mathrm{MPa}$. The investigated non-reinforced clay slope has a factor of safety of 1.13 and a displacement of $15.6 \mathrm{~cm}$ in dry soil. The foundation soil of slope is saturated but the soil of embankment is unsaturated. All of the models are used at the suction of $10 \mathrm{kPa}$ and moisture of $25 \%$, according to SWCC (Turning point).

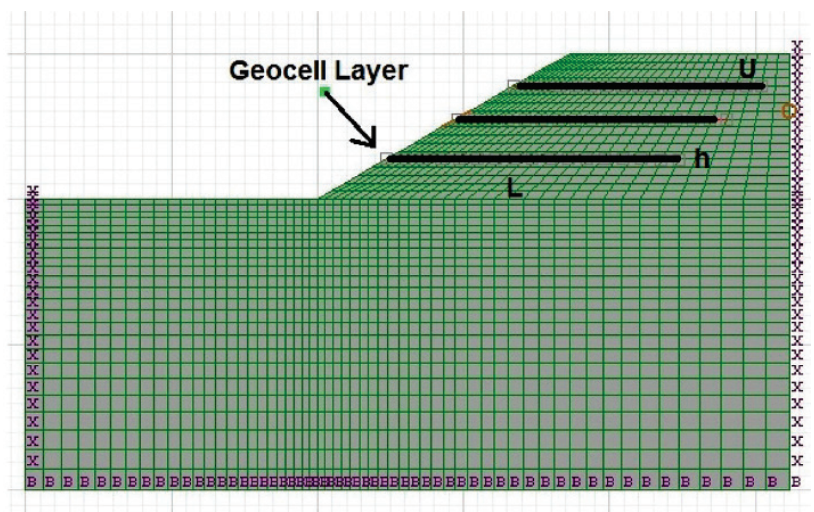

Figure 6 The view of the reinforced slope with geocell studied in the research

\subsection{Validation}

The Barcelona Basic Model has been applied to Flac software by making the following assumptions.

1 - Net mean stress is equal to total mean stress, which is a practical assumption. 2- Soil suction is a variable affecting both soil strength and stiffness. 


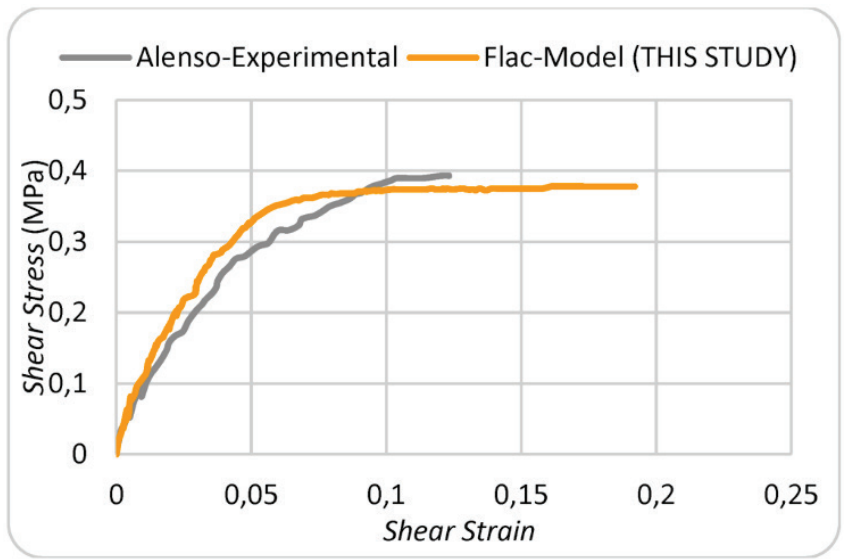

Figure 7 Validation of the generated model in Flac software using the Barcelona Basic Model (suction of $90 \mathrm{kPa}$ )

A single element with axisymmetric conditions is considered for the simulation to model triaxial tests on the soil of the reference model. Boundary conditions of the single element have been taken into account. In practice, the single element exhibits one quarter of the triaxial sample being tested, which has been fixed in two other directions. According to Fig. 7, the curve obtained in the study conducted by Alonso is negligibly different from the curve obtained from the results of Flac software where the error is less than $5 \%$. The validation results suggest that the proposed model has an acceptable capability of explaining the behavior of unsaturated soil.

\section{EFFECT OF NUMBER OF GEOCELL LAYERS ON THE STABILITY OF REINFORCED SLOPE}

As shown in Fig. 8, an increase in the number of reinforcement layers enhances the factor of safety. Such a behavior can be attributed to the extension of adjoining zone and higher frictional resistance at the soil-geocell interface. Therefore, higher horizontal shear stress occurs in the soil behind the failure surface. In these conditions, bending stiffness and shear strength of reinforcements are also enhanced, thus avoiding horizontal displacements of soil.

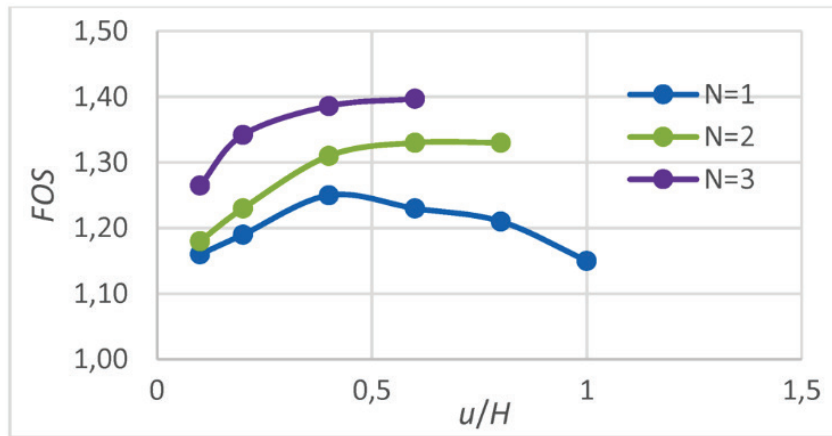

Figure 8 Variations in the improvement factor of safety slope against the number of geocell layers

Improvement rate of the factor of safety based on the number of layers mainly depends on the depth of the first geocell reinforcement layer. This can be addressed as the ability of the first reinforcement layer to avoid the propagation of sliding surface which can consequently affect the overall slope stability. The performance of other geocell layers is largely associated with the improvement of lateral deformation of slope. Geocell length is $22 \mathrm{~m}$ and its thickness $0.5 \mathrm{~m}$. In $u / H=0.6$ by increasing the number of layers, FOS increases up to $13.8 \%$. (Fig. 8).

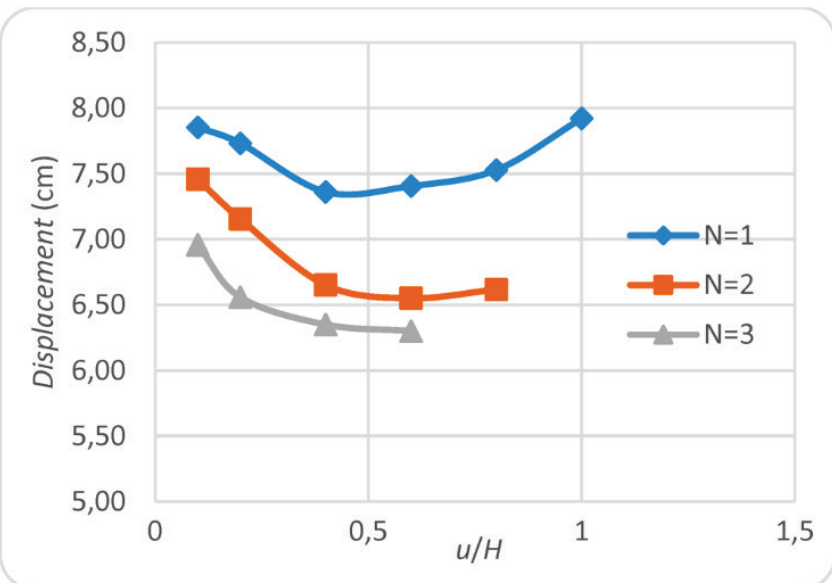

Figure 9 Displacement variations against the number of geocell layers

As it can be observed in Fig. 9, an increase in $\mathrm{u} / \mathrm{H}$ from 0.2 to 0.6 causes a reduction in slope displacement by $22.6 \%$. Therefore, the results reveal that the first geocell layer functions as a wide slap and yields the redistribution of load in a broader surface and reduction in the stress intensity. The first geocell layer dramatically transfers the force to the lower parts and consequently leads to force transfer to other geocell layers along with the enhancement of the stability performance.

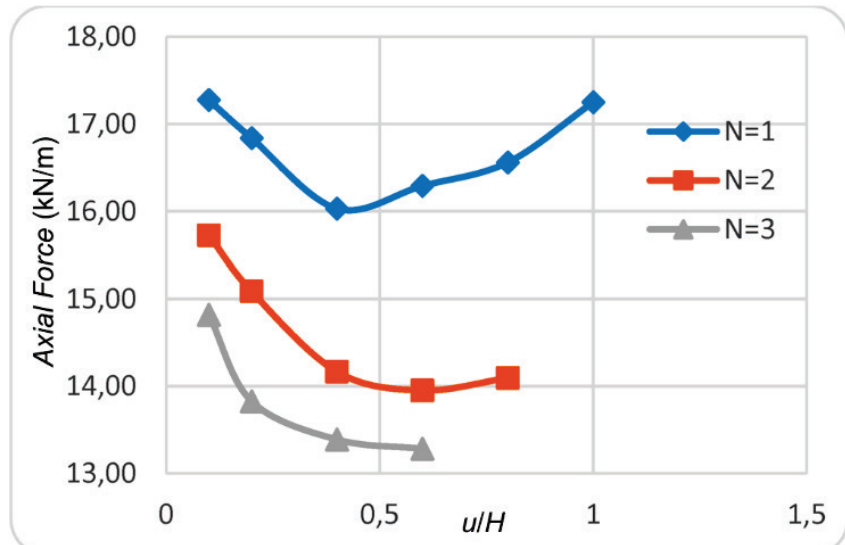

Figure 10 Variation in the axial force of geocell layer versus the number of geocell layers

Based on Fig. 10, as the number of geocell layers increases, the axial force of geocell layer is noticeably reduced. In fact, receiving the main portion of forces in the first geocell layer, the moment of inertia is largely delivered to the first geocell layer and it is consequently diminished in other layers (Fig. 11). 


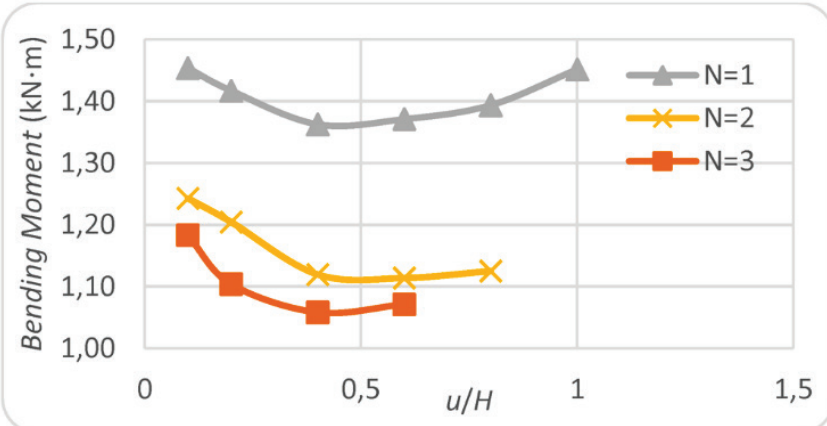

Figure 11 Variations of the bending moment in geocell layer against the number of geocell layers

\section{EFFECT OF LENGTH OF GEOCELL LAYERS ON THE STABILITY OF REINFORCED SOIL}

Fig. 12 shows the variations of the improvement factor of slope affected by the length of reinforcement layer. The obtained results demonstrate that as the reinforcement layer increases in length, the factor of safety is enhanced as well. This is attributed to the increase in restraining, interface, tensile, and bending strengths by increasing the length of geocell layer. $u / H=0.2$ and thickness of geocell is considered to be $0.5 \mathrm{~m}$.

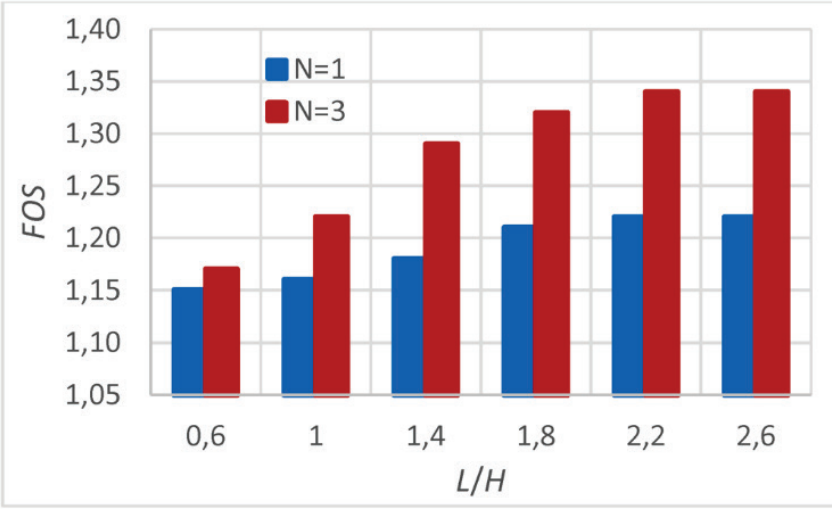

Figure 12 Variations of slope improvement factor affected by the length of reinforcement layer

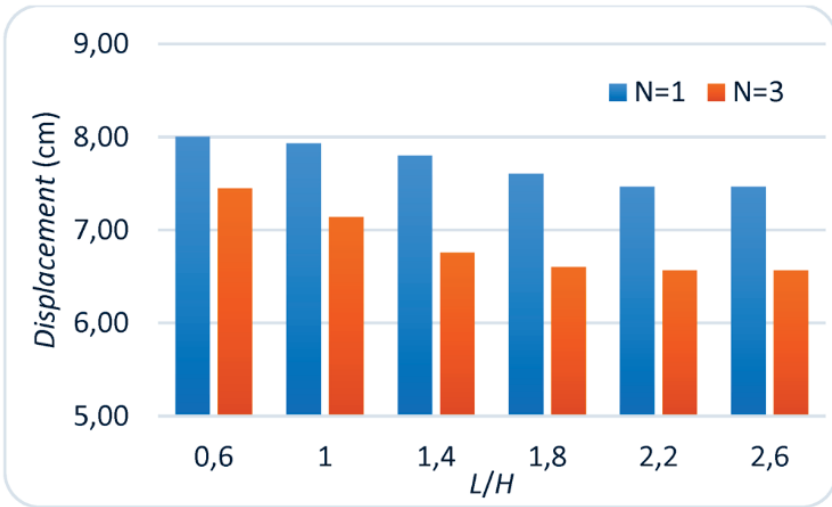

Figure 13 Variation of slope displacement affected by the length of reinforcement layer

As indicated in Fig. 13, the displacement of slope is reduced by lengthening the geocell layer. Increasing $L / H$ ratio from 0.6 to 2.6 in the geocell layer, the displacement is reduced by $7.32 \%$. Furthermore, the displacement is declined by $13.81 \%$ in three geocell layers. At $L / H=1.8$, as the number of layers increases from 1 to 3 , the displacement is reduced by $15.2 \%$.

Increasing $L / H$ from 0.6 to 2.6 in one geocell layer, the axial force is reduced in geocell by $7 \%$. Moreover, it is reduced by $14.44 \%$ in other three layers of geocell. At $L / H=$ 2.6 , increasing the number of layers from 1 to 3 , the axial force is declined by $5.18 \%$. The effect of length on three layers of geocell is more tangible than on one layer of geocell (Fig. 14).

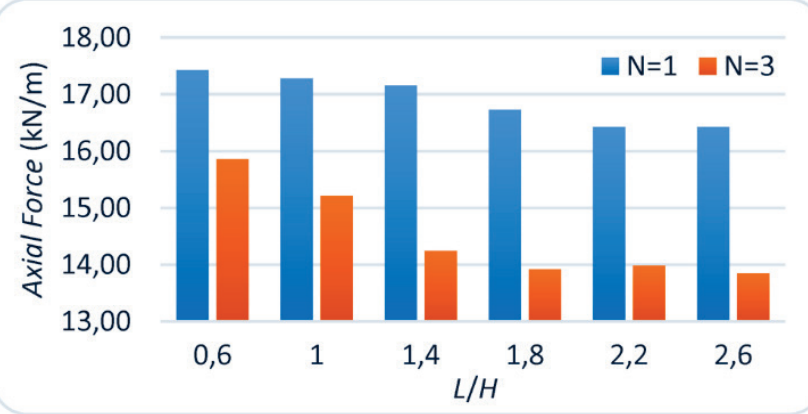

Figure 14 Variation of axial force of geocell layer affected by the length of reinforcement layer

According to the investigation of bending moment, it is declined approximately by $7 \%$ and $11.4 \%$ in one and three geocell layers, respectively. At $L / H=2.6$, the bending moment is reduced by $20 \%$ by increasing the number of geocell layers (Fig. 15).

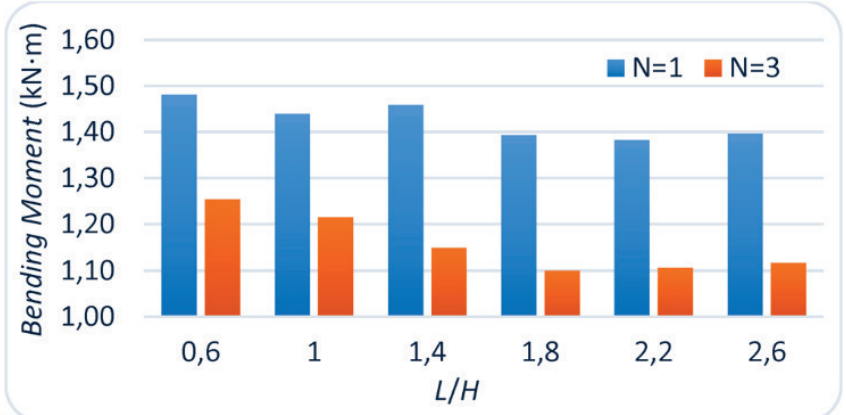

Figure 15 Variation of the bending moment in geocell layer affected by the length of reinforcement layer

\section{INVESTIGATION OF CHANGES IN THE THICKNESS OF THE GEOCELL LAYER ON STABILITY OF REINFORCED SLOPE}

As expected, the coefficient reliability increases (FOS) with increasing elevation of the geocell layer (Fig. 16).

Maximum slope velocity and also shear strain occur at the level of the slopes located above the geocell, and in the shear height below the geocell layer, resistance to the lateral movement of the soil increases. In $u / H=0.6$, the maximum effect of the thickness of the geocell layer on coefficient reliability is about $8 \%$. The investigations are carried out under conditions of a geocell layer of 18 meters in length. 


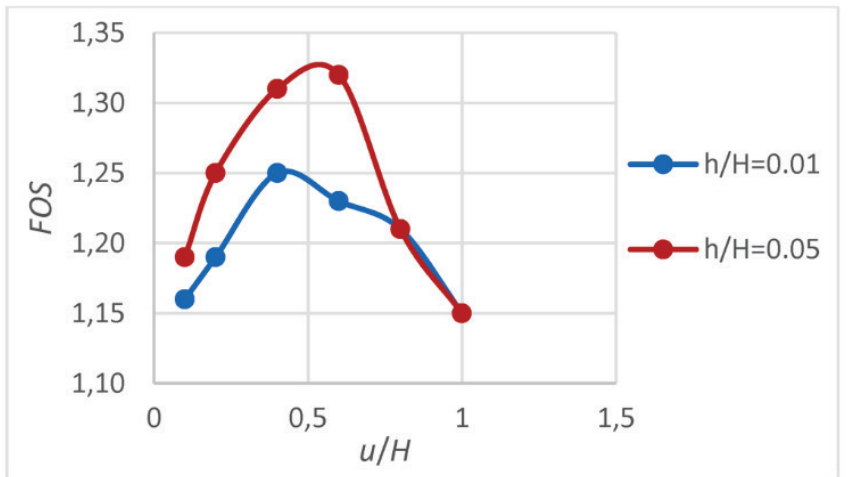

Figure 16 The factor of safety slope affected by the thickness change of the geocell layer

By increasing the height of the geocell layer, the moment of inertia increases and, consequently, the bending moment of geocell reinforcement increases as well. In this condition, the behavior of geocell layer is identical to a deep beam, reducing the reinforcement deformation and consequently declining the lateral deformation of slope. On the other hand, the reinforcement efficiency is dramatically dropped by decreasing the height of geocell layer.

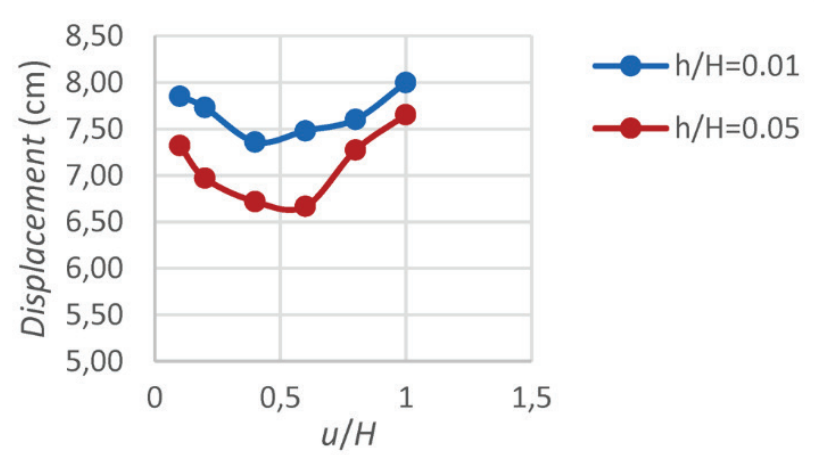

Figure 17 The displacement of the slope affected by the thickness change of the geocell layer

According to Fig. 17, the highest displacement rate occurs in the ratio $u / H=1$. In this case, most displacements occur in the geocell sublayer and the geocell layer does not have any effect on controlling the forces due to the weight of the soil. On the other hand, if the geocell layer in this case has a very deep depth of surface $(u / H=1)$ the amount of lateral displacement in the upper part of the slope increases and all displacement occurs in the upper part of the slope. This reduces the shear coefficient reliability, and in this case it also behaves as a not reinforced slope. In $u / H=0.2$, the increase in thickness reduces the displacement of $10 \%$, which has the least effect on the increase compared to the rest of the ratios. By reducing the height of the geocell's surface, the reinforcement efficiency decreases in the redistribution of the load at a wider and deeper level and the three-dimensional array of geocell, such as plate reinforcements, is shown (Fig. 17). By increasing the thickness of the geocell, the amount of moment inertia increases and as a result, the amount of bending moment reinforcing geocell increases. In this case, the behavior of the geocell layer is like a deep beam, which reduces the reinforcing shift and, as a result, reduces the lateral shift of the slope. On the other hand, by decreasing the height of the geocell layer, the amount of reinforcing output extremely decreases. The maximum increase in force at $u / H$ $=0.6$ is about $13 \%$ and the least effect on $u / H=0.8$ is about $8 \%$ (Fig. 18).

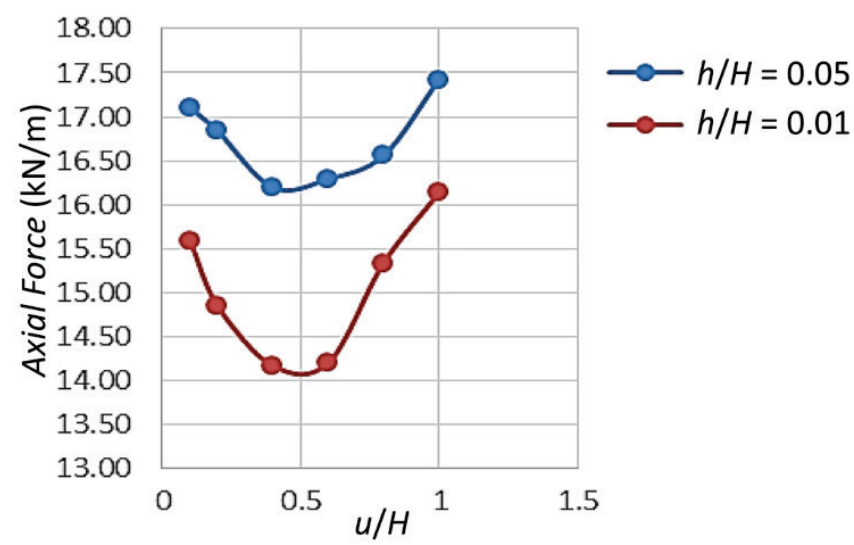

Figure 18 Variation of axial force of geocell affected by the thickness of reinforcement layer

The beam element, due to its height and modulus of elasticity, can create an inertia momentum and cause a bending moment to resist a change in shape. It seems that in this case, the geocell layer of the beam simulated can act like a wide slab and cause a redistribution of load and load transfer at a larger and deeper level of the soil. The depth of placement of the first layer of geocell has a great role in increasing the shear coefficient reliability and reducing the lateral deformations of the slope. The results show that by reducing the thickness of the geocell reinforcement, the created moment of inertia decreases and, as a result, the bending moment of reinforcing decreases (Fig. 19). At $u / H=$ 0.2 , an increase in the bending momentum of about $20 \%$ occurred with increasing geocell thickness. In $u / H=1$, the increase in bending momentum is $10.4 \%$.

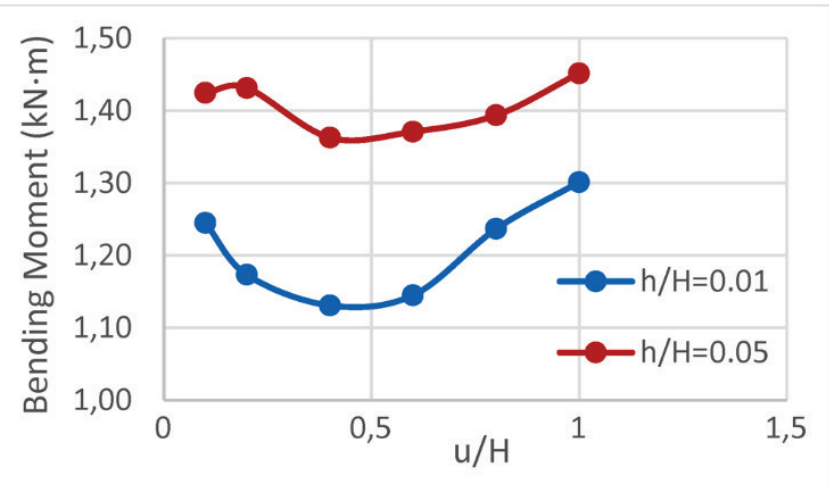

Figure 19 Variations of the bending moment in geocell layer affected by the suction change

\section{CONCLUSION}

The results show that the effective depth of the geocell layer is in the mid-sectional heights of the slope, and the increase in the number of geocell layers has a greater effect 
on the stability of the slope rather than the increase in geocell length. By locating the first layer of the geocell in an effective area, the development of the defect plates decreases and leads them to a greater depth. In this regard, other geocell reinforcers behave like a slab that transmits vertical pressures from the highest layer into the deeper depth of the soil. In fact, the first layer causes the relation between geocell layers to transfer strain. If the length of the geocell is very small relative to the sliding surface, the flexural moment of the geocell layer is negated. The reason for this is due to the very small amount of moment formed by the tensile force of the geocell layer.

Increasing $L / H$ from 0.6 to 2.6 in one geocell layer, the axial force is reduced in geocell by $7 \%$. Moreover, it is reduced by $14.44 \%$ in other three layers of geocell. At $L / H=$ 2.6 , increasing the number of layers from 1 to 3 , the axial force is declined by $5.18 \%$. The effect of length on three layers of geocell is more tangible than on one layer of geocell.

The effective length of the reinforcing layer is equal to the length of the geocell, which is located inside the slip surface, and in this area a great deal of tensile, shear and flexural force is mobilized in the geocell. On the other hand, the length of the reinforcing layer should be somewhat higher than the length of the slip surface, in order to prevent the development of possible slip surfaces, and also provide an appropriate length to counteract the pulling out of the reinforcing layer against the forces involved. The improvement in the coefficient of reliability based on the number of geocell layers depends largely on the depth of the first reinforcing layer. The reason for this is the ability of the first layer of reinforcing to prevent the spread of the slip surface, which can affect the stability of the entire slope. The performance of other layers of geocell can be greatly correlated with improvement of lateral displacement of the slope. The results show that by increasing the geocell reinforcing moment, the created inertia of moment decreases, and results in a decrease in the reinforcing flexural moment. In this case, the behavior of the reinforcing geocell approaches to the reinforcing plate and its efficiency decreases.

\section{REFERENCES}

[1] Hegde, A. M. \& Sitharam, T. G. (2015). Three-dimensional numerical analysis of geocell-reinforced soft clay beds by considering the actual geometry of geocell pockets. Canadian Geotechnical Journal, 52(9): 1396-1407. https://doi.org/10.1139/cgj-2014-0387

[2] Skinner, G. D. \& Roweb, R. K. (2005). Design and behaviour of a geosynthetic reinforced retaining wall and bridge abutment on a yielding foundation. Geotextiles and Geomembranes, 23(3), 234-260. https://doi.org/10.1016/j.geotexmem.2004.10.001

[3] Leshchinsky, B. (2012). Effects of Geocell Confinement on Strength and Deformation Behavior of Gravel. Journal of Geotechnical and Geoenvironmental Engineering, 139(2), 340-352. https://doi.org/10.1061/(ASCE)GT.1943-5606.0000757

[4] Zornberg, J. G. et al. (2003). Strain Distribution within Geosynthetic-Reinforced Slopes. Journal of Geotechnical and Geoenvironmental Engineering, 129(1), 32-45.
https://doi.org/10.1061/(ASCE)1090-0241(2003)129:1(32)

[5] Lazhar, B., Hacene, B., \& Jarir, Y. (2011). Internal Stability Analysis of Reinforced Earth Retaining Walls. Geotech Geol Eng, 29, 443-452. https://doi.org/10.1007/s10706-011-9390-4

[6] Chen, R. H. \& Chiu, Y. M. (2008). Model Tests of Geocell Retaining Structures. Geotextiles and Geomembranes, 26(1), 56-70. https://doi.org/10.1016/j.geotexmem.2007.03.001

[7] Chen, R. H., Huang, Y. W., \& Huang, F. C. (2013). Confinement Effect of Geocells on Sand Samples Under Triaxial Compression. Geotextiles and Geomembranes, 37(1), 35-44. https://doi.org/10.1016/j.geotexmem.2013.01.004

[8] Fakher, A. \& Jones, C. J. F. P. (2001). When the bending stiffness of geosynthetic reinforcement is important. Geosynthetics International, 8(5), 445-460. https://doi.org/10.1680/gein.8.0202

[9] Zhang, L., Zhao, M. H., Zou, X. W., \& Zhao, H. (2009). Deformation analysis of geocell reinforcement using winkler model. Comput Geotech, 36(6), 977-983. https://doi.org/10.1016/j.compgeo.2009.03.005

[10] Zhang, L., Zhao, M. H., Zou X. W., \& Zhao, H. (2010). Analysis of geocell reinforced mattress with consideration of horizontal vertical coupling. Comput Geotech, 37(6), 748-756. https://doi.org/10.1016/j.compgeo.2010.06.001

[11] Dash, S. K., Rajagopal, K., \& Krishnaswamy, N. R. (2007). Behaviour of geocell reinforced sand beds under strip loading. Canadian Geotechnical Journal, 44(7), 905-916. https://doi.org/10.1139/t07-035

[12] Yang, X. M., Han, J., Parsons, R. L., \& Leshchinsky, D. (2010). Three dimensional numerical modeling of single geocellreinforced sand. Front. Archit. Civ. Eng. China, 4(2), 233-240. https://doi.org/10.1007/s11709-010-0020-7

[13] Roy, K., Hawlader, B., Kenny, S., \& Moorec, I. (2015). Finite element modeling of lateral pipeline-soil interactions in dense sand. Canadian Geotechnical Journal, 53(3), 490-504. https://doi.org/10.1139/cgj-2015-0171

[14] Sheng, D. (2011). Review of fundamental principles in modelling unsaturated soil behavior. Computers and Geotechnics, 38(6), 757-776. https://doi.org/10.1016/j.compgeo.2011.05.002

[15] Sheng, D. (2011). Constitutive Modelling of Un saturated Soils: Discussion of Fundamental Principles. Unsaturated soils, 1, 91-112.

[16] Uchaipichat, A. (2011). Effective stress parameter of unsaturated granular soils. International Conference on Mechanical, Automobile and Robotics Engineering, (ICMAR 2011). http://psrcentre.org/images/extraimages/ 31.\%201011182.pdf

[17] Fredlund, D. G., Morgenstern, N. R., \& Widger, A. (1978). Shear strength of unsaturated soils. Canadian Geotechnical Journal, 15(3), 313-321. https://doi.org/10.1139/t78-029

[18] Yang, K. H., Thuo, J. N., Chen, J.-W., \& Liu, C. N. (2018). Failure investigation of a geosynthetic-reinforcedsoil slope subjected to rainfall. Geosynthetics International, 26(1), 1-62. https://doi.org/0.1680/jgein.18.00035

[19] Oberg, A. L. \& Sallfors, G. A. (1996). Rational approach to the determination of the shear strength parameters of unsaturated soils. Proc. $1^{\text {st }}$ Intl Conf. Unsaturated Soils, Paris, 151-158. http://worldcat.org/isbn/9054105836

[20] Bolzon, G., Schrefer, A., \& Zienkiewicz, O. C. (1996). Elastoplastic soil constitutive laws generalizedto partially saturated states. Geochnique, 46(2), 279-289. https://doi/10.1680/ geot.1996.46.2.279

[21] Wu, L. Z., Huang, R. Q., Xu, Q., Zhang, L. M., \& Li, H. L. (2015). Analysis of physical testing of rainfall-induced soil slope failures. Environ Earth Sci, 73(12), 8519-8531. 
https://doi.org/10.1007/s12665-014-4009-8

[22] Khalili, N. \& Khabbaz, M. H. (1998). A unique relationship for $\chi$ for the determination of the shear strength of unsaturated soils. Geotechnique, 48(5), 681-687. https://doi.org/10.1680/geot.1998.48.5.681

[23] Alonso, E. E., Gens, A., \& Josa, A. (1990). A constitutive model for partially saturated soils. Geotechnique, 40(3), 405430. https://doi.org/10.1680/geot.1990.40.3.405

[24] Sreedeep, S. \& Singh, D. N. (2006). Nonlinear curve-fitting procedures for developing soil-water characteristic curves. Geotech Test J., 29(5), 409-418. https://doi.org/10.1520/GTJ14104

[25] Van Genuchten, M. Y. (1980). A closed form equation for predicting the hydraulic conductivity of unsaturated soils. Soil Sci Soc Am J, 44, 892-898. https://doi.org/10.2136/sssaj1980 .03615995004400050002x

[26] Cheng, Y. M., Lansivaara, T., \& Wie, W. B. (2007). Twodimensional slope stability analysis by limit equilibrium and strength reduction methods. Computers and Geotechnics, 34, 137-150. https://doi.org/10.1016/j.compgeo.2006.10.01

[27] Zhou, H. \& Wen, X. (2008). Model studies on geogrid e or geocell-reinforced sand cushion on soft soil. Geotextiles and Geomembranes, 26(3), 231-238. https://doi.org/10.1016/j.geotexmem.2007.10.002

[28] Pokharel, S. K., Han, J., Leshchinsky, D., Parsons, R. L., \& Halahmi, I. (2010). Investigation of factors influencing behavior of single geocell-reinforced bases under static loading. Geotextiles and Geomembranes, 28, 570-578. https://doi.org/10.1016/j.geotexmem.2010.06.002

[29] Mehdipour, I., Ghazavi, M., \& Moayed, R. Z. (2013). Numerical study on stability analysis of geocell reinforced slopes by considering the bending effect. Geotext. Geomembr, 37, 23-34. https://doi.org/10.1016/j.geotexmem.2013.01.001

[30] Zhao, M. H., Zhang, L., Zou, X. J., \& Zhao, H. (2009). Research progress in two direction composite foundation formed by geocell reinforced mattress and gravel piles. Chinese Journal of Highway and Transport, 29(1), 1-10. http://zgglxb.chd.edu.cn/EN/Y2009/V22/I1/1

[31] Madhavi Latha, G., Rajagopal, K., \& Krishnaswamy, N. R. (2006). Experimental and theoretical investigations on geocell supported embankments. International Journal of Geomechanics, ASCE, 6, 30-35.

https://doi.org/10.1061/(ASCE)1532-3641(2006)6:1(30)
Authors' contacts:

Behnam Mehdipour, PhD

Department of Civil Engineering,

Najafabad Branch, Islamic Azad University, Najafabad,

Iran zipaton@yahoo.com

Hamid Hashemolhosseini, PhD, Professor

Department of Civil Engineering,

Isfahan University of Technology, Isfahan, Iran

hamidh@cc.iut.ac.ir

Bahram Nadi, PhD, Assistant Professor

(Corresponding author)

Department of Civil Engineering,

Najafabad Branch, Islamic Azad University, Najafabad, Iran nadi@pci.iaun.ac.ir

\section{Masoud Mirmohamadsadeghi,}

$\mathrm{PhD}$, Associated Professor of Civil Engineering

Department of Water and Natural Environment,

Isfahan Higher Education and Research Institute (IHEARI),

Ministry of Energy, Isfahan, I. R. Iran

msadeghi84@yahoo.com 